Check for updates

Cite this: RSC Adv., 2019, 9, 22129

Received 12th May 2019

Accepted 3rd July 2019

DOI: $10.1039 /$ c9ra03557e

rsc.li/rsc-advances

\title{
Study of the reaction of ninhydrin with tyrosine in gemini micellar media
}

\author{
Dileep Kumar (D)*ab and Malik Abdul Rub ${ }^{c}$
}

This paper reports the study of the ninhydrin and L-tyrosine (Tyr) reaction in gemini micellar media. The aim of the study was to see the influence of different parameters on the reaction rate, including the influence of reactant concentration, temperature and $\mathrm{pH}$. Spectrophotometric and conductometric techniques were employed to record the absorption of the product formed and $\mathrm{cmc}$ values as a function of the surfactants, respectively. The effect of varied surfactant concentrations on the reaction rate was also investigated. The quantitative treatment of the rate constant $\left(k_{\psi}\right)$ vs. surfactant concentration was carried out on the basis of the pseudo-phase model suggested by Martinek et al., Menger and Portnoy, and established by Bunton. Micellar binding parameters and thermodynamic parameters have been calculated and are discussed in detail. A plausible reaction mechanism that is consistent with observed kinetic data has been proposed.

\section{Introduction}

Surfactants consist of an amphiphilic chemical structure, having a preference toward interfacial adsorption at low concentrations of the surfactant in an aqueous medium. They self-associate to form an aggregated structure beyond a certain critical concentration. Their shape, size, and aggregated structure depend on different parameters that include surfactant concentration, salt, temperature, etc. A small range of concentration at which the formation of an aggregated structure occurs is called the critical micelle concentration ( $\mathrm{cmc}$ ), and this process of self-association of surfactant monomers into a micelle is referred to as micellization. ${ }^{1-4}$ Surfactants are used extensively in several industry and research fields..$^{5-7}$ They find widespread use in household items and in the chemical industry due to their promising properties such as low cmc, high surface activity, super wetting ability, high dispersion, etc. $^{8-10}$ The formation of a micelle, a characteristic property of surfactants, has various applications fundamentally as well as in applied fields. It is important in pharmaceutical technology as micelles play roles in several biochemical membranes and pharmacological systems due to their dual behavior (hydrophilic head and hydrophobic tail). ${ }^{11-14}$

Ninhydrin is the name employed by Abderhalden and Schmidt ${ }^{15}$ for 1,2,3-triketohydrindene. They have given the

${ }^{a}$ Division of Computational Physics, Institute for Computational Science, Ton Duc Thang University, Ho Chi Minh City, Vietnam

${ }^{b}$ Faculty of Applied Sciences, Ton Duc Thang University, Ho Chi Minh City, Vietnam. E-mail: dileepkumar@tdtu.edu.vn; Tel: +84943720085

${ }^{c}$ Chemistry Department, Faculty of Science, King Abdulaziz University, Jeddah-21589, Saudi Arabia compound this name because of its peculiar color reaction with $\alpha$-amino acids and amines. In 1910, ninhydrin, or what is more scientifically known as 2,2-dihydroxyindan-1,3dione (as, in the presence of water, ninhydrin exists as its hydrate) was also called Ruhemann's reagent (the reagent was first discovered by Ruhemann) (Scheme 1). ${ }^{16}$

$\alpha$-Amino acids react with ninhydrin at different rates, but they all give the same product of diketohydrindylidenediketohydrindamine (DYDA), known as Ruhemann's purple. To obtain better results, efforts are regularly being carried out involving CTAB surfactants, solvents and salts by researchers/scientists and the color of the product obtained has been affected. ${ }^{17-20}$ However, studies on the interaction of amino acids with ninhydrin in the presence of dimeric gemini surfactants are scarce. Researchers are still waiting for their advanced developments.

At the present time, there has been a fast increasing interest in proteins due to the number of their applications and uses in several aspects including in biochemistry and biotechnology. ${ }^{21,22}$ Amino acids play a significant role in our
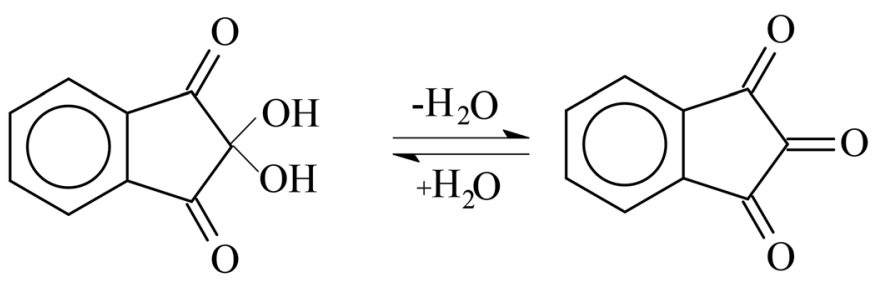

(N)

Scheme 1 Structure of ninhydrin. 


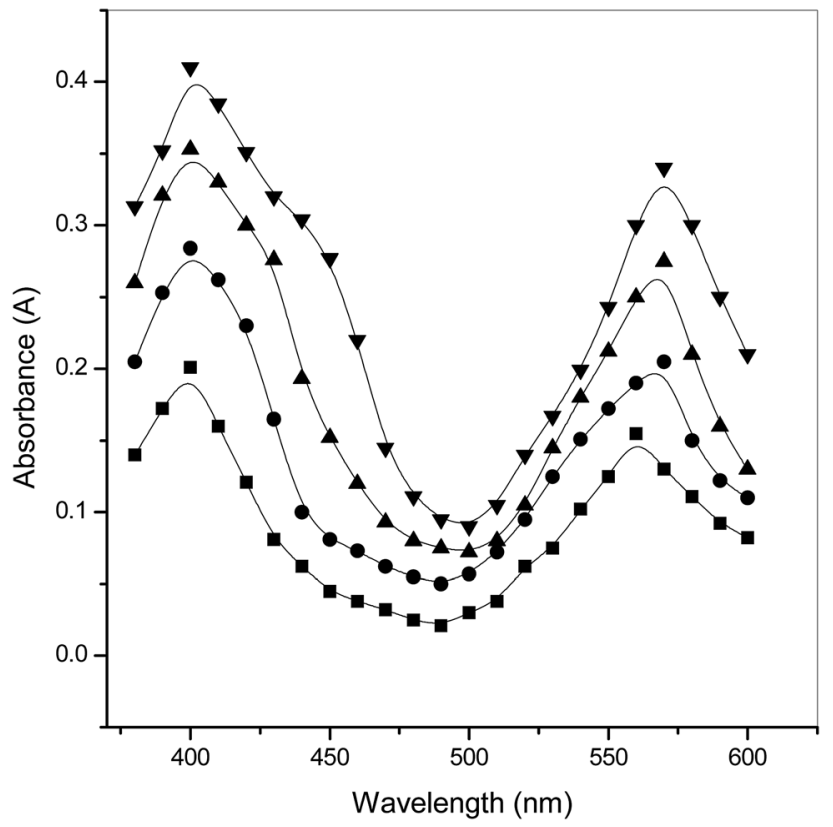

Fig. 1 UV-visible spectra of the product formed during the reaction of ninhydrin and Tyr in aqueous solution and in 16-s-16 gemini surfactants: aqueous (), 16-6-16 (-), 16-5-16 ( $\mathbf{\Delta}), 16-4-16(\boldsymbol{\nabla})$. Conditions: [ninhydrin] $=5.0 \mathrm{mM}$, [Tyr] $=0.1 \mathrm{mM}$, $[16-\mathrm{s}-16]=30 \times 10^{-2} \mathrm{mM}$ temp. $=353 \mathrm{~K}$ and $\mathrm{pH}=5.0$.

Table 1 Dependence of the rate constants $\left(k_{\Psi}\right)$ on $\mathrm{pH}$ and temperature for the reaction of ninhydrin $(5 \mathrm{mM})$ and Tyr $(0.1 \mathrm{mM})$ in the presence of gemini surfactants

\begin{tabular}{|c|c|c|c|c|}
\hline \multirow[b]{2}{*}{$\mathrm{pH}$} & \multirow[b]{2}{*}{ Temperature (K) } & \multicolumn{3}{|c|}{$10^{5} k_{\psi}\left(\mathrm{s}^{-1}\right)$} \\
\hline & & $16-6-16^{a}$ & $16-5-16^{a}$ & $16-4-16^{a}$ \\
\hline \multirow[t]{5}{*}{5.0} & 343 & 8.2 & 10.1 & 11.7 \\
\hline & 348 & 10.0 & 11.8 & 13.5 \\
\hline & 353 & 13.5 & 14.6 & 15.5 \\
\hline & 358 & 18.2 & 20.7 & 22.4 \\
\hline & 363 & 22.5 & 25.3 & 27.7 \\
\hline 4.0 & 353 & 4.0 & 6.5 & 8.1 \\
\hline 4.5 & & 6.5 & 8.0 & 10.4 \\
\hline 5.0 & & 13.5 & 14.6 & 15.5 \\
\hline 5.5 & & 16.0 & 17.1 & 18.0 \\
\hline 6.0 & & 17.5 & 18.5 & 19.4 \\
\hline
\end{tabular}

Activation parameters, rate

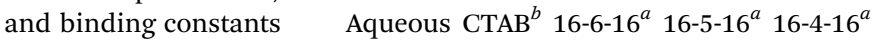

\begin{tabular}{lllrrr}
\hline$E_{\mathrm{a}}\left(\mathrm{kJ} \mathrm{mol}^{-1}\right)^{d}$ & 60.2 & 48.2 & 49.9 & 47.1 & 43.3 \\
$\Delta H^{\#}\left(\mathrm{~kJ} \mathrm{~mol}^{-1}\right)^{d}$ & 57.4 & 45.4 & 47.1 & 44.3 & 40.5 \\
$-\Delta S^{\#}\left(\mathrm{~J} \mathrm{~K}^{-1} \mathrm{~mol}^{-1}\right)^{d}$ & 159.5 & 191.1 & 190.6 & 190.0 & 189.2 \\
$10^{5}{\mathrm{rate} \mathrm{constant}\left(\mathrm{s}^{-1}\right)^{d}}^{3}$ & 11.5 & 14.3 & 13.5 & 14.6 & 15.5 \\
$10^{3} k_{\mathrm{m}}\left(\mathrm{s}^{-1}\right)^{c}$ & - & 5.0 & 4.0 & 4.8 & 5.5 \\
$K_{\mathrm{N}}\left(\mathrm{M}^{-1}\right)^{c}$ & - & - & 63.9 & 61.7 & 59.5 \\
$K_{\mathrm{T}}\left(\mathrm{M}^{-1}\right)^{c}$ & - & - & 70.0 & 64.0 & 56.0
\end{tabular}

${ }^{a}[16-s-16]=30 \times 10^{-2} \mathrm{mM} .{ }^{b}[\mathrm{CTAB}]=20 \mathrm{mM} .{ }^{c}$ At $353 \mathrm{~K} .{ }^{d}$ The literature values of $E_{\mathrm{a}}, \Delta H^{\#}, \Delta S^{\#}, k_{\mathrm{m}}$ and the rate constant in aqueous and in CTAB are from ref. 65 .
Table 2 Dependence of the rate constants $\left(k_{\Psi}\right)$ on [Tyr] and [ninhydrin] for the reaction of ninhydrin and Tyr in the presence of 16-s-16 surfactant $\left(30 \times 10^{-2} \mathrm{mM}\right)$ at a temperature of $353 \mathrm{~K}$ and $\mathrm{pH} 5.0$

\begin{tabular}{lclll}
\hline & & \multicolumn{3}{l}{$10^{5} k_{\psi}\left(\mathrm{s}^{-1}\right)$} \\
\cline { 3 - 5 }$[\mathrm{Tyr}](\mathrm{mM})$ & {$[$ Ninhydrin] $(\mathrm{mM})$} & $16-6-16$ & $16-5-16$ & $16-4-16$ \\
\hline 0.1 & 5 & 13.5 & 14.6 & 15.5 \\
0.15 & & 13.4 & 14.4 & 15.6 \\
0.2 & & 13.5 & 14.3 & 15.7 \\
0.25 & & 13.3 & 14.6 & 15.5 \\
0.3 & 5 & 13.5 & 14.5 & 15.4 \\
0.1 & 10 & 13.5 & 14.6 & 15.5 \\
& 15 & 20.1 & 22.7 & 25.2 \\
& 20 & 26.3 & 29.8 & 32.4 \\
& 25 & 31.4 & 35.5 & 37.5 \\
& 30 & 34.6 & 38.4 & 42.3 \\
& 35 & 37.2 & 42.1 & 45.1 \\
& 40 & 39.4 & 44.3 & 47.0 \\
& & 40.5 & 46.0 & 48.5
\end{tabular}

lives and have one of the most distinctive objectives of all medicines in living beings. They control the divergence of activity in the field of medical science, e.g. in metabolic process, information transfer, etc. Therefore, estimation of amino acids is highly significant in the evaluation of a protein structure.

Among the surfactants, gemini have been known for a long time, and they have been enormously studied by researchers. ${ }^{23-26}$ This is due to their superior properties and advanced applications. Gemini surfactants contain two heads (hydrophilic) and two tails (hydrophobic) in one molecule. That is, two conventional surfactant

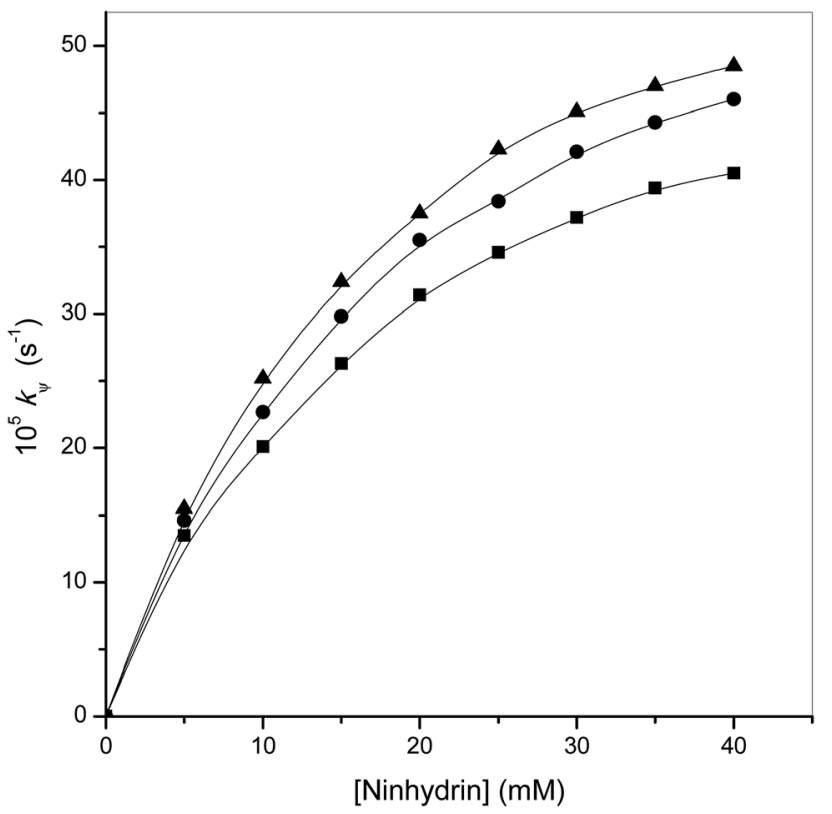

Fig. 2 Observed rate constant $\left(k_{\psi}\right)$ against [ninhydrin] plots for the reaction of ninhydrin and Tyr in the presence of gemini surfactants: 166-16 ( $\mathbf{\square}), 16-5-16(0), 16-4-16(\boldsymbol{\Delta})$. Conditions: [Tyr] = 0.1 mM, [16-s$16]=30 \times 10^{-2} \mathrm{mM}$, temp. $=353 \mathrm{~K}$ and $\mathrm{pH}=5.0$. 


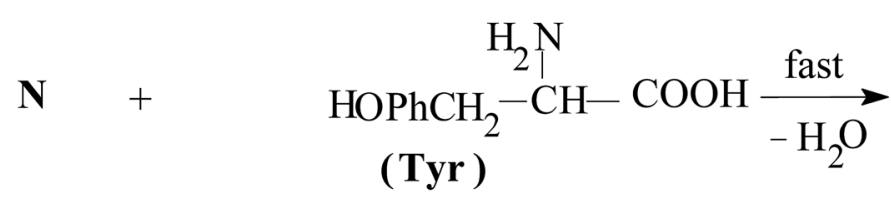

1<smiles>O=C(O)C(Cc1ccccc1)N=c1c(=O)c2ccccc2c1=O</smiles>

fast

$\downarrow$<smiles>NC(=O)C1=C(N)c2ccccc2C1=O</smiles>

(2-amino-indanedione, $\left.B_{1}\right)$

$\mathrm{HOPhCH}_{2} \mathrm{CHO}$

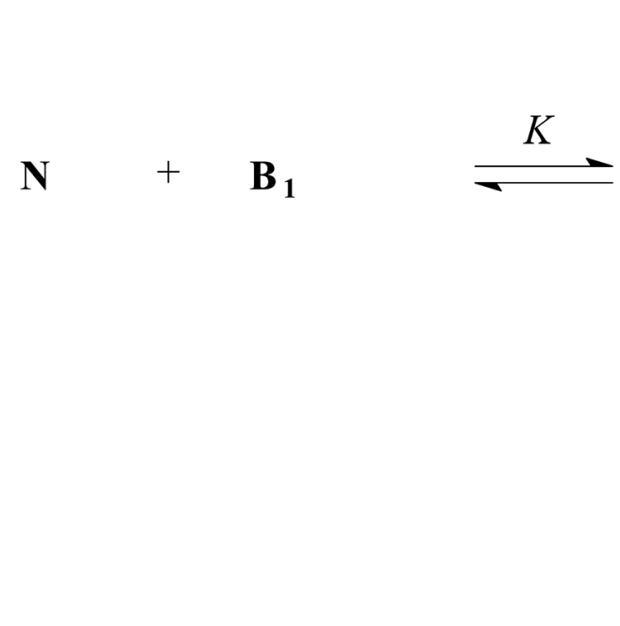

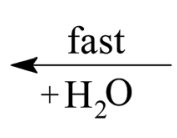

(Schiff base)<smiles>O=C(O)C(Cc1ccccc1)=NC1=C(O)c2ccccc2C1=O</smiles>

(Schiff base)

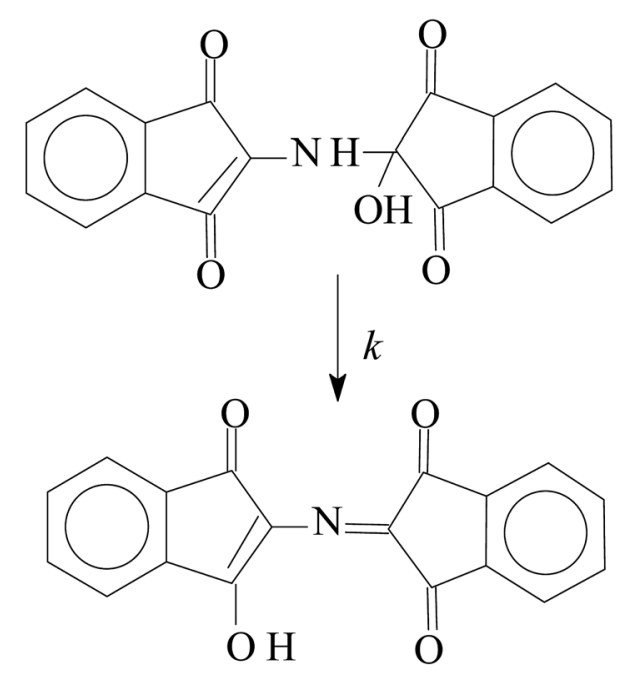

(DYDA)

Scheme 2 Tyr-ninhydrin reaction mechanism.

monomers are joined together via a spacer. ${ }^{27-31}$ Gemini surfactants show lower cmc, better surface activity, super wetting power and a low Krafft point over traditional single chain surfactants (single hydrophilic head and single hydrophobic tail). ${ }^{24,32-35}$ Gemini surfactants appeal for present consideration in surface science due to their unusual properties. They have been utilized in various fields for diverse purposes, e.g. in skin care, analytical uses, solubilizing agents, etc. ${ }^{36,37}$

Numerous articles have been published in the scientific literature on the physico-chemical activities/properties of gemini surfactants. These observed that the gemini surfactants were superior on all fronts to the single surfactants. ${ }^{38-43}$ However, the impact of gemini surfactants on reaction rates has been paid relatively less attention and is required to be focused on more for further development of the surfactants. Taking the above facts into consideration, we have synthesized and characterized three cationic gemini surfactants (designated as m-s-m; $\mathrm{m}(16)$ and $s(4-6)$ refer to the alkyl chain length and the spacer, respectively). In order to obtain better insight and results, a study of the Tyr and ninhydrin reaction was conducted in gemini micellar media using a range of techniques and models and was discussed.

\section{Experimental}

\subsection{Materials and equipment}

Double-distilled conductivity water was utilized throughout the experiments. All stock solutions of Tyr, ninhydrin and the gemini surfactants were made in $\mathrm{CH}_{3} \mathrm{COOH}-\mathrm{CH}_{3} \mathrm{COONa}$ buffer solution at 
Table 3 Effect of [16-s-16] gemini surfactant on the rate constant $\left(k_{\psi}\right)$ for the reaction of ninhydrin $(5 \mathrm{mM})$ and Tyr $(0.1 \mathrm{mM})$ at a temperature of $353 \mathrm{~K}$ and $\mathrm{pH} 5.0$, as well as the comparison with the calculated rate constant ( $\left.k_{\Psi \text { cal }}\right)$

\begin{tabular}{|c|c|c|c|c|c|c|c|c|c|}
\hline $10^{2}[16-s-16](\mathrm{mM})$ & $10^{5} k_{\psi}\left(\mathrm{s}^{-1}\right)$ & $10^{5} k_{\psi \mathrm{cal}}\left(\mathrm{s}^{-1}\right)$ & $\frac{k_{\Psi}-k_{\Psi \mathrm{cal}}}{k_{\Psi}}$ & $10^{5} k_{\psi}\left(\mathrm{s}^{-1}\right)$ & $10^{5} k_{\psi \mathrm{cal}}\left(\mathrm{s}^{-1}\right)$ & $\frac{k_{\Psi}-k_{\Psi \mathrm{cal}}}{k_{\Psi}}$ & $10^{5} k_{\psi}\left(\mathrm{s}^{-1}\right)$ & $10^{5} k_{\psi \mathrm{cal}}\left(\mathrm{s}^{-1}\right)$ & $\frac{k_{\Psi}-k_{\Psi \mathrm{cal}}}{k_{\Psi}}$ \\
\hline 0.0 & 11.5 & - & - & 11.5 & - & - & 11.5 & - & - \\
\hline 5.0 & 11.7 & - & - & 11.9 & - & - & 12.3 & - & - \\
\hline 10.0 & 12.1 & 12.0 & +0.01 & 12.4 & 12.6 & -0.02 & 12.9 & 12.9 & 0 \\
\hline 40.0 & 13.6 & 13.7 & -0.01 & 14.8 & 15.0 & -0.01 & 15.6 & 15.8 & -0.01 \\
\hline 50.0 & 13.7 & 13.9 & -0.01 & 14.9 & 15.2 & -0.02 & 15.7 & 15.9 & -0.01 \\
\hline 60.0 & 13.7 & 13.7 & 0 & 14.9 & 14.8 & +0.01 & 15.7 & 15.7 & 0 \\
\hline 80.0 & 13.8 & 14.0 & -0.01 & 15.0 & 15.3 & -0.02 & 15.8 & 15.8 & 0 \\
\hline 100.0 & 13.8 & 14.1 & -0.02 & 15.1 & 15.1 & 0 & 15.9 & 15.7 & +0.01 \\
\hline 250.0 & 13.9 & 13.8 & +0.01 & 15.3 & 15.3 & 0 & 16.1 & 16.3 & -0.01 \\
\hline 2000.0 & 17.4 & - & - & 19.6 & - & - & 21.1 & - & - \\
\hline 2500.0 & 19.1 & - & - & 21.6 & - & - & 23.5 & - & - \\
\hline 3000.0 & 22.2 & - & - & 25.1 & - & - & 27.5 & - & - \\
\hline
\end{tabular}

$\mathrm{pH}$ 5.0. L-Tyrosine (98.0\%) was used as received from s.d. fine. $\mathrm{CH}_{3} \mathrm{COOH}$ (99.0\%), $\mathrm{CH}_{3} \mathrm{COONa}(99.0 \%)$ and ninhydrin (99.0\%) were employed as supplied from Merck without additional purification. $\quad N, N$-dimethylcetylamine $(>95.0 \%), \quad$ 1,4-dibromobutane $(>98 \%)$, 1,5-dibromopentane (>98\%) and 1,6-dibromohexane $(>97 \%)$ were bought from Fluka. Other chemicals used in the present study were of AR grade. To measure the $\mathrm{pH}$, an ELICO $\mathrm{pH}$ meter was used. Alkanediyl- $\alpha, \omega$-bis(dimethylcetylammonium bromide), 16-s-16, was synthesized via a procedure mentioned previously. ${ }^{44,45}$ The achieved products were purified several times using ethyl acetate. Product yields were found to be more than $90 \%$. Afterwards, the products were placed in a vacuum oven. In addition, they were kept in vacuum desiccators containing phosphorous pentaoxide (because they are excellent absorbers of $\mathrm{H}_{2} \mathrm{O}$ ) for more than 48 hours before their use. The identification of products was ascertained by elemental analysis and ${ }^{1} \mathrm{H}$ NMR. ${ }^{\mathbf{4 4 , 4 5}}$

\subsection{Electrical conductivity}

The electrical conductivity was measured as a function of the concentration of the surfactant. For this experiment, a Systronics conductivity meter (Ahmedabad, India) was utilized throughout the study. The experimental temperature was kept constant at 303 $\mathrm{K}$ and $353 \mathrm{~K}$. The electrode cell used was made up of glass with the cell constant at $1.0 \mathrm{~cm}^{-1}$. The electrode was calibrated by $\mathrm{KCl}$ within the required range of concentration. The intersection at two straight lines of the curve between the specific conductivities and the surfactant concentrations gives the desired cmc value. ${ }^{46}$ The cmc value of the pure gemini surfactants determined in our present case is in good agreement with the data reported earlier. ${ }^{47}$ The cmc values of the surfactants determined with and without ninhydrin and Tyr (i.e. water, water + ninhydrin + Tyr) are provided below: (a) $[16-6-16](\mathrm{mM}): 0.043,0.025$ (at $303 \mathrm{~K}) ; 0.058,0.045$ (at $353 \mathrm{~K}$ )

(b) $[16-5-16]$ (mM): 0.034, 0.022 (at $303 \mathrm{~K}) ; 0.055,0.030$ (at $353 \mathrm{~K}$ )

(c) $[16-4-16](\mathrm{mM}): 0.032,0.018$ (at $303 \mathrm{~K}) ; 0.043,0.020$ (at $353 \mathrm{~K}$ ).

\subsection{Kinetic procedure and rate constant determination}

A single beam UV-visible spectrophotometer (SHIMADZUmodel UV mini 1240, Kyoto, Japan) was used for

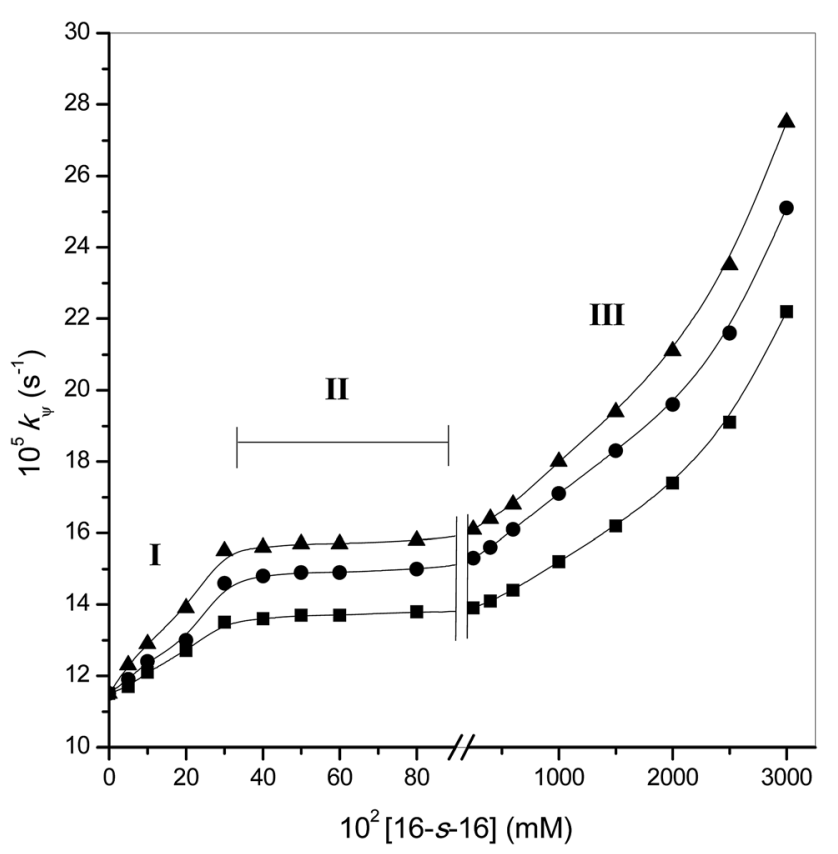

Fig. 3 Observed rate constant against [16-s-16] plots for the reaction

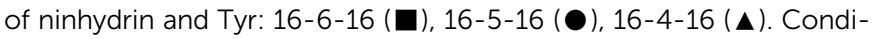
tions: [ninhydrin] $=5 \mathrm{mM}$, $[\mathrm{Tyr}]=0.1 \mathrm{mM}$, temp. $=353 \mathrm{~K}$ and $\mathrm{pH}=5.0$. 
spectroscopic measurements on the interaction of ninhydrin with Tyr in a surfactant medium. The volumes of Tyr, buffers and surfactant (if required) were kept in a round bottomed three-necked flask in a water bath at $353 \mathrm{~K}$. Nitrogen gas was flowed through the mixture to create inertness inside the flask. The required quantity of ninhydrin solution was added to the flask to initiate the reaction. The absorbance of the product formed was recorded at definite time intervals at $\lambda_{\max } 570 \mathrm{~nm}$. The rate constants $\left(k_{\psi}, \mathrm{s}^{-1}\right)$ in the gemini surfactants were determined by employing a program (computer based). All measurements were carried out in triplicate at least. The rest of the information on the kinetic methodology can be seen in the articles published earlier. ${ }^{\mathbf{4 8 - 5 1}}$

\subsection{Spectra of the product formed}

Spectra of the ninhydrin and Tyr reaction in two systems was noted on a UV-visible spectrophotometer. All the absorption spectra of the product formed were measured in a quartz cuvette (with a thickness of $10 \mathrm{~mm}$ and a slit width of $1 \mathrm{~mm}$ ). Spectra were recorded in the wavelength range from $380 \mathrm{~nm}$ to $600 \mathrm{~nm}$ and are presented in pictorial form in Fig. 1. Graphitic profiles between $A$ and $\lambda$ showed that the absorbance was found to be greater in the surfactants compared to in aqueous solution at the same maximum absorption band $\left(\lambda_{\max }=570 \mathrm{~nm}\right)$. This shows that the product formed in both media is the same.

\section{Results and discussion}

The observed rate constant values at various $\mathrm{pHs}$ in the presence of the surfactants evaluated are shown in Table 1. The concentration of the reactants (ninhydrin and Tyr) and the temperature were kept constant. Table 1 confirms that $k_{\psi}$ increases up to $\mathrm{pH}$ 5.0, and beyond $\mathrm{pH} 5.0$ there is almost no change in $k_{\psi}$. Therefore, all of the experiments were performed at $\mathrm{pH}$ 5.0.

Studies were performed at several initial concentrations of Tyr at $353 \mathrm{~K}$ by fixing other experimental parameters. The values of the rate constant were evaluated in the surfactants and are tabulated in Table 2. After a close look at Table 2, it can be easily concluded that the order of reaction is firstorder with respect to Tyr as the rates do not depend on the initial concentration of Tyr (eqn (1)).

$$
\text { Rate }=\frac{\mathrm{d}[\mathrm{DYDA}]}{\mathrm{d} t}=k_{\Psi}[\mathrm{Tyr}]
$$

Kinetic experiments were carried out in micellar media (gemini surfactants) at a different set of ninhydrin concentration by fixing the rest of the parameters. The rate constant increases with an increase in the ninhydrin concentration. The observed values of $k_{\psi}$ are shown in Table 2 . The curves between the rate constant and ninhydrin concentration were of non-linear feature and crossed through the origin. This is shown in Fig. 2. It can be safely concluded that the reaction showed fractional-order kinetics with respect to the ninhydrin concentration.
The influence of temperature has been studied on the title reaction by varying the temperature (range: $343 \mathrm{~K}$ to 363 $\mathrm{K})$ with a fixed concentration of the reactants and fixed $\mathrm{pH}$. The experiment was carried out in gemini micelles. The rate value increased with the increase in temperature. These data are presented in Table 1, and were used to determine different thermodynamic parameters with the help of the Eyring equation.

\section{Mechanism}

Ninhydrin reacts with various amino groups (except proline) at different rates, but they all produce the DYDA product. ${ }^{52}$ However, the amount of product formed in the reactions is dependent on several factors including reactant concentration, reaction medium, $\mathrm{pH}$ and temperature. In the current study, the mechanism of the reaction has been proposed for the study of ninhydrin and Tyr. This is shown in Scheme 2. By considering Scheme 2, the reaction proceeds though the attack of a lone pair of electrons of an amino nitrogen (tyrosine) on a carbonyl group (ninhydrin) to give a Schiff base. The Schiff base, being unstable, hydrolyses to give 2-aminoindanedione $\left(\mathrm{B}_{1}\right)$ and an aldehyde. Then $\mathrm{B}_{1}$ reacts with another ninhydrin molecule to give DYDA.

\section{Reaction in gemini surfactants}

The $k_{\psi}$ values evaluated at different concentrations of surfactants in the study of ninhydrin and Tyr are listed in Table 3 and are shown graphically in Fig. 3. The same respective first- and fractional-order paths in the tyrosine concentration and in the ninhydrin concentration were followed in the gemini surfactants as in those of in aqueous solutions. Fig. 1 confirms that the absorption maximum of the product stays the same in the surfactant system. This leads to the conclusion that the mechanism of reaction does not vary in any way between the two systems.

Quantitative treatment of $k_{\psi} v s$. [surfactant] may be elucidated using the model (pseudo-phase) suggested by Martinek et al. ${ }^{53}$ and by Menger and Portnoy ${ }^{54}$ that was established by Bunton. ${ }^{55,56}$ According to the pseudo-phase model, the reaction occurs in bulk aqueous and micellar pseudo phases. Under the set reaction situation, Scheme 3 can be presented as below.

$$
\begin{aligned}
& \mathrm{T}_{\mathrm{W}}+\mathrm{D}_{\mathrm{n}} \stackrel{\mathrm{K}_{\mathrm{T}}}{\rightleftharpoons} \mathrm{TD}_{\mathrm{n}} \\
& \mathrm{N}_{\mathrm{W}}+\mathrm{D}_{\mathrm{n}} \stackrel{\mathrm{K}_{\mathrm{N}} \rightleftharpoons}{\rightleftharpoons} \mathrm{N}_{\mathrm{m}} \\
& \mathrm{T}_{\mathrm{w}}+\mathrm{N}_{\mathrm{w}} \stackrel{\mathrm{k}_{\mathrm{w}}^{\prime}}{\longrightarrow} \text { DYDA } \\
& \mathrm{TD}_{\mathrm{n}}+\mathrm{N}_{\mathrm{m}} \stackrel{\mathrm{k}_{\mathrm{m}}^{\prime}}{\longrightarrow} \mathrm{DYDA}
\end{aligned}
$$

Scheme 3 Study of the ninhydrin and Tyr reaction. 
$K_{\mathrm{T}}$ and $K_{\mathrm{N}}$ refer to the respective tyrosine-micelle binding constant and ninhydrin-micelle binding constant. $T$ and $D_{n}$ stand for the concentration of Tyr and the micellized surfactant ([gemini $]_{\mathrm{T}}$-cmc), respectively. $k_{\mathrm{w}}^{\prime}$ and $k_{\mathrm{m}}^{\prime}$ are the respective pseudo-first-order rate constants that refer to the bulk and micellar pseudo-phases.

Rate eqn (1) and Scheme 3 give eqn (2):

$$
k_{\Psi}=\frac{k_{\mathrm{w}}^{\prime}+k_{\mathrm{m}}^{\prime} K_{\mathrm{T}}\left[\mathrm{D}_{\mathrm{n}}\right]}{1+K_{\mathrm{T}}\left[\mathrm{D}_{\mathrm{n}}\right]}
$$

Eqn (2) results in eqn (3)

$$
k_{\Psi}=\frac{k_{\mathrm{w}}[\mathrm{N}]+\left(K_{\mathrm{T}} k_{\mathrm{m}}-k_{\mathrm{w}}\right) M_{\mathrm{N}}^{\mathrm{S}}\left[\mathrm{D}_{\mathrm{n}}\right]}{1+K_{\mathrm{T}}\left[\mathrm{D}_{\mathrm{n}}\right]}
$$

where, $[\mathrm{N}]$ represents the ninhydrin concentration. $k_{\mathrm{w}}=k_{\mathrm{w}}^{\prime} /\left[\mathrm{N}_{\mathrm{w}}\right]$ and $k_{\mathrm{m}}=k_{\mathrm{m}}^{\prime} / M_{\mathrm{N}}^{\mathrm{S}}$ are the second-order rate constants.

$M_{\mathrm{N}}^{\mathrm{S}}$ is the molar ratio of bound ninhydrin to the micellar head group and is presented by eqn (4),

$$
M_{\mathrm{N}}^{\mathrm{S}}=\frac{\left[\mathrm{N}_{\mathrm{m}}\right]}{\left[\mathrm{D}_{\mathrm{n}}\right]}
$$

$M_{\mathrm{N}}^{\mathrm{S}}$ was determined by considering the equilibrium, as given by eqn (5) below.

$$
\begin{gathered}
\mathrm{N}_{\mathrm{w}}+\mathrm{D}_{\mathrm{n}} \stackrel{K_{\mathrm{N}}}{\rightleftharpoons} \mathrm{N}_{\mathrm{m}} \\
K_{\mathrm{N}}=\frac{\left[\mathrm{N}_{\mathrm{m}}\right]}{\left[\mathrm{N}_{\mathrm{w}}\right]\left(\left[\mathrm{D}_{\mathrm{n}}\right]-\left[\mathrm{N}_{\mathrm{m}}\right]\right)}
\end{gathered}
$$

and the mass balance is:

$$
[\mathrm{N}]=\left[\mathrm{N}_{\mathrm{w}}\right]+\left[\mathrm{N}_{\mathrm{m}}\right]
$$

Calculation of $k_{\mathrm{m}}$ (rate constant for a micellar medium) and $K_{\mathrm{T}}$ (tyrosine-micelle binding constant) from eqn (3) requires a cmc value of the gemini surfactants under the set of kinetic experimental conditions. The required $\mathrm{cmc}$ values have been determined using a conductivity technique. The values of $k_{\mathrm{m}}$ and $K_{\mathrm{T}}$ were calculated at several presumed values of $K_{\mathrm{N}}$ by a computer program. The obtained data are located in Table 1. Fitting $K_{\mathrm{T}}, k_{\mathrm{m}}$ and $K_{\mathrm{N}}$ to eqn (3) supports the validity of the equation. Table 3 confirms the good agreement between $k_{\psi}$ and $k_{\psi c a l}$, and this authenticates the validity of the proposed reaction mechanism.

Critical micelle concentration ( $\mathrm{cmc}$ ) is one of the most reliable and useful parameters. The cmc value is employed to establish a quantitative relationship between the physicochemical parameters and the structure of the surfactant. In the present study, a rate constant has been evaluated for the title reaction below and above the cmc value of the surfactant solutions. A detailed account of the activity of the gemini surfactants is given below.

Considering segment I of Fig. 3, where the surfactant concentrations are below the cmc value, $k_{\psi}$ should not change. However, the rate constant increased. The observed catalysis may, therefore, be due to the formation of pre-micelles by the substrate. Pre-micelle formation and catalysis below the $\mathrm{cmc}$ value of the surfactants have been reported in earlier published articles. ${ }^{57,58}$

Segment II (Fig. 3) shows that no reaction took place (i.e. the $k_{\psi}$ value remained almost constant). Segments I and II of the $k_{\psi}$ vs. [16-s-16] plots where [gemini] varies from 0 to $400 \times 10^{-5} \mathrm{M}$ are akin to their monomeric counterparts (single hydrophilic head and hydrophobic tail). This can be seen only when the substrates are absolutely micellar bound with the micellar assembly continually being unaffected. ${ }^{59}$ The characteristic of segment II is unchanged for all surfactants and the rate constant follows the order $16-4-16>16-5-16>16-6-16$ for all concentrations. This is not the first time where 16-4-16 among all the three gemini surfactants has given the best outcomes. 164-16 gave the best results previously as well. ${ }^{44}$

After levelling-off, the $k_{\psi}$ value increases further at higher gemini concentrations. Perhaps this is due to the association with a variation of micellar structures. It is well established that the surfactants self-associate into aggregates in aqueous solution above the $\mathrm{cmc}$ value. Generally, the aggregates are rotund, globular micelles. However, under appropriate conditions of concentration, salinity, temperature, the presence of counter ions, etc., the spherical micelles can undergo uniaxial growth to form flexible worm-like micelles. ${ }^{60}$ Furthermore, in the case of gemini surfactants, the extent of aggregate growth and the changes of the shapes of the micelles depend on the length of the spacer(s) as well. Cryo-TEM measurements from solutions of 16-s-16 clearly show the transitions upon increasing $s$ with the sequence of structures of micelles being: vesicles + elongated micelles $\rightarrow$ elongated micelles $\rightarrow$ spheroidal micelles. ${ }^{61}$ Thus, the micellar growth is more pronounced the shorter the spacer unit, and this is most likely due to the increasing geometrical constraints in the formation of aggregates with decreasing length of the spacer unit. At higher [gemini], variations in these micellar structures occur, which have been confirmed by ${ }^{1} \mathrm{H}$ NMR spectral studies. ${ }^{62}$ Thus, variations in the micellar morphologies give a distinct reaction atmosphere (less polar); this is the consequence of increasing $k_{\psi}$ sharply (Fig. 3). The same is true for all gemini surfactants and the difference is only in the extent of the $k_{\psi}$ enhancement, and this depends on the spacer.

\section{Thermodynamic parameters}

Thermodynamic parameters were calculated within the temperature range of $343 \mathrm{~K}$ to $363 \mathrm{~K}$ using the Eyring equation in study of ninhydrin and Tyr in gemini micellar media. The thermodynamic parameters are listed in Table 1. Upon comparison of the data with aqueous solutions (Table 1), we find that $\Delta H^{\#}$ reduces with a more negative $\Delta S^{\#}$ in the presence of the gemini surfactants, compared to in aqueous solutions. This reduction in the parameters $\left(\Delta H^{\#}\right.$ and $\left.\Delta S^{\#}\right)$ takes place not only through the adsorption of both ninhydrin and Tyr on the micellar surface but also through the stabilization of the activated state. A meaningful mechanistic description of these apparent parameters is impossible because the rate constant, 
$k_{\psi}$, does not denote a single elementary kinetic step; it is a complex function of true rate, binding constants and ionization constants.

Looking at the data in Table 1, we can observe that gemini surfactants catalyze and accelerate the title reaction more than aqueous media. Furthermore, improvement in the values of thermodynamic parameters and rate constants using gemini surfactants takes place at concentrations ca. 67 times less than using cetyltrimethylammonium bromide (CTAB). Thus, the importance of the study is increased due to the use of very small quantities of the gemini surfactants that are required to perform the reaction. This is an important point to be noted regarding the use of gemini surfactants (cost effectiveness, as well as environmental toxicity).

\section{Conclusions}

In the current study, we have synthesized and characterized three cationic gemini surfactants (designated as $\mathrm{m}-s-\mathrm{m}$; where $\mathrm{m}$ and $s$ refer to the alkyl chain length and the spacer, respectively). Experiments between ninhydrin and Tyr were performed in the gemini surfactants by studying the reaction using a UVvisible spectrophotometer. The study of ninhydrin and Tyr in gemini micellar media could be carried out successfully by the pseudo-phase model. 16-s-16 gemini surfactants were found to be extremely more valuable in applications in all respects than aqueous solution and traditional surfactants. ${ }^{63,64}$

A key point to be noted is that, under the identical experimental situation, a much lower gemini concentration (below the cmc value) was adequate to catalyze and accelerate the rate than in the aqueous medium. This special feature of the gemini surfactants allows them to be used in low amounts in household items and in cosmetic purposes/products to overcome potential skin irritation. Gemini surfactants could be beneficial from the environmental toxicity point of view due to the low release of surfactant quantity.

\section{Conflicts of interest}

There are no conflicts of interest to declare.

\section{Acknowledgements}

The Division of Computational Physics, Institute for Computational Science, Ton Duc Thang University, Ho Chi Minh City, Vietnam is highly acknowledged.

\section{References}

1 D. Kumar and M. A. Rub, J. Mol. Liq., 2017, 238, 389.

2 M. F. Ahmed, M. R. Molla, M. Saha, I. Shahriar, M. S. Rahman, M. A. Halim, M. A. Rub, M. A. Hoque and A. M. Asiri, $R S C$ Adv., 2019, 9, 6556.

3 D. Kumar, N. Azum, M. A. Rub and A. M. Asiri, J. Mol. Liq., 2018, 262, 86.

4 D. Kumar, M. A. Rub, N. Azum and A. M. Asiri, J. Phys. Org. Chem., 2018, 31, e3730.
5 S. Qi, S. Roser, K. J. Edler, C. Pigliacelli, M. Rogerson, I. Weuts, F. V. Dycke and S. Stokbroekx, Pharm. Res., 2013, 30, 290.

6 M. Akram, S. Anwar, F. Ansari, I. A. Bhat and Kabir-ud-Din, RSC Adv., 2016, 6, 21697.

7 M. A. Rub, N. Azum, D. Kumar, M. A. Asiri and H. M. Marwani, J. Chem. Thermodyn., 2014, 74, 91.

8 Y. Moroi, Micelles, Theoretical and Applied Aspects, Plenum Press, New York, USA, 1992.

9 M. R. Amin, S. Mahbub, M. R. Molla, M. M. Alam, M. F. Hossain, S. Rana, M. A. Rub, M. A. Hoque and D. Kumar, J. Chem. Eng. Data, 2019, 64, 2750.

10 Y. Wang, C. Gao and S. Yang, Water Sci. Technol., 2015, 72, 837.

11 D. Kumar, S. Hidayathulla and M. A. Rub, J. Mol. Liq., 2018, 271, 254.

12 L. L. Schramm, E.-N. Stasiuk and D.-G. Marangoni, Annu. Rep. Prog. Chem., Sect. C: Phys. Chem., 2003, 99, 3.

13 S. Mahbub, M. A. Rub, M. A. Hoque, M. A. Khan and D. Kumar, J. Phys. Org. Chem., 2019, DOI: 10.1002/poc.3967.

14 D. Kumar and M. A. Rub, J. Mol. Liq., 2017, 240, 253.

15 E. Abderhalden and H. S. Schmidt, Hoppe-Seyler's Z. Physiol. Chem., 1913, 85, 143.

16 S. Ruhemann, J. Chem. Soc., 1910, 97, 2025.

17 Kabir-ud-Din, M. Bano and I. A. Khan, J. Surf. Sci. Technol., 2002, 18, 113.

18 Kabir-ud-Din and W. Fatma, J. Surf. Sci. Technol., 2002, 18, 129.

19 Kabir-ud-Din, J. K. J. Salem, S. Kumar and Z. Khan, J. Colloid Interface Sci., 1999, 215, 9.

20 F. Friedman, J. Agric. Food Chem., 2004, 52, 385 and references cited therein.

21 E. D. Goddard and K. P. Ananthapadmanabhan, Interactions of Surfactants with Polymers and Proteins, CRC Press, Florida, 1993.

22 J. L. Brash and T. A. Horbett, Proteins at Interfaces II: Fundamentals and Applications, American Chemical Society, Washington, DC, 1995.

23 C. A. Bunton, L. Robinson, J. Schaak and M. F. Stam, J. Org. Chem., 1971, 36, 2346.

24 R. Zana, M. Benrraou and R. Rueff, Langmuir, 1991, 7, 1072. 25 E. Alami, G. Beinert, P. Marie and R. Zana, Langmuir, 1993, 9, 1465.

26 R. Zana and Y. Talmon, Nature, 1993, 362, 228.

27 F. M. Menger and C. A. Littau, J. Am. Chem. Soc., 1991, 113, 1451.

28 Y. Han and Y. Wang, Phys. Chem. Chem. Phys., 2011, 13, 1939 and reference therein.

29 D. Kumar and M. A. Rub, J. Mol. Liq., 2018, 250, 329.

30 D. Kumar and M. A. Rub, J. Mol. Liq., 2018, 269, 1.

31 D. Kumar and M. A. Rub, Tenside, Surfactants, Deterg., 2018, 55, 78.

32 M. Akram, I. A. Bhat and Kabir-ud-Din, RSC Adv., 2015, 5, 102780.

33 S. Das, S. Mondal and S. Ghosh, RSC Adv., 2016, 6, 30795. 
34 L. Tavano, M. R. Infante, M. Abo Riya, A. Pinazo, M. P. Vinardell, M. Mitjans, M. A. Manresa and L. Perez, Soft Matter, 2013, 9, 306.

35 R. Zana, Curr. Opin. Colloid Interface Sci., 1996, 1, 566.

36 M. Dreja and B. Tieke, Langmuir, 1998, 14, 800.

37 F. Li and M. J. Rosen, J. Colloid Interface Sci., 2000, 224, 265.

38 P. Shi, H. Zhang, L. Lin, C. Song, Q. Chen and Z. Li, RSC Adv., 2019, 9, 3224.

39 N. Azum, A. M. Asiri, M. A. Rub, A. A. P. Khan, A. Khan, M. M. Rahman, D. Kumar and A. O. Al-Youbi, Colloid J., 2013, 75, 235.

40 D. Kumar and M. A. Rub, J. Phys. Org. Chem., 2019, 32, e3918.

41 D. Kumar and M. A. Rub, J. Phys. Org. Chem., 2019, 32, e3946.

42 M. J. Rosen and D. J. Tracy, J. Surfactants Deterg., 1998, 1, 547.

43 S. He, X. Liu, P. Yan, A. Wang, J. Su and X. Su, RSC Adv., 2019, 9, 4908.

44 Kabir-ud-Din, W. Fatma, Z. A. Khan and A. A. Dar, J. Phys. Chem. B, 2007, 111, 8860.

45 S. De, V. K. Aswal, P. S. Goyal and S. Bhattacharya, J. Phys. Chem., 1996, 100, 11664.

46 P. Mukerjee and K. J. Mysels, Critical Micelle Concentrations of Aqueous Surfactant Systems, Superintendent of Documents, Washington, DC, 1971.

47 Kabir-ud-Din and W. Fatma, J. Phys. Org. Chem., 2007, 20, 440.

48 M. Akram, D. Kumar and Kabir-ud-Din, Colloids Surf., B, 2012, 94, 220.

49 M. Akram, D. Kumar and Kabir-ud-Din, Colloids Surf., A, 2013, 428, 92.
50 D. Kumar and M. A. Rub, Tenside, Surfactants, Deterg., 2019, DOI: $10.3139 / 113.110635$.

51 D. Kumar and M. A. Rub, J. Mol. Liq., 2019, 274, 639.

52 M. M. Joullie, T. R. Thompson and N. H. Nemeroff, Tetrahedron, 1991, 47, 8791.

53 K. Martinek, A. K. Yatsimirski, A. P. Osipov and I. V. Berezin, Tetrahedron, 1973, 29, 963.

54 F. M. Menger and C. E. Portnoy, J. Am. Chem. Soc., 1967, 89, 4698.

55 C. A. Bunton, J. Mol. Liq., 1997, 72, 231.

56 C. A. Bunton, Surfactants in Solution, ed. K. L. Mittal and D. O. Shah, Plenum Press, New York, 1991, vol. 2.

57 G. Cerichelli, G. L. Mancini, L. Luchetti, G. Savelli and C. A. Bunton, Langmuir, 1994, 10, 3982.

58 Y. Zhang, X. Li, J. Liu and X. Zeng, J. Dispersion Sci. Technol., 2002, 23, 473.

59 G. Savelli, R. Germani and L. Brinchi, Reactions and Synthesis in Surfactant Systems, Surfactant Science Series, ed. J. Texter, 2001, Marcel Dekker, New York, vol. 100.

60 D. F. Evans and H. Wennerstrom, The Colloidal Domain where Physics, Chemistry, Biology and Technology Meet, $\mathrm{VCH}$, New York, 1994.

61 D. Danino, Y. Talmon and R. Zana, Langmuir, 1995, 11, 1448.

62 L. Brinchi, R. Germani, L. Goracci, G. Savelli and C. A. Bunton, Langmuir, 2002, 18, 7821.

63 M. N. Khan, Micellar Catalysis; Surfactant Science Series, CRC Press, New York, 2006, vol. 133.

64 J. H. Fendler and E. J. Fendler, Catalysis in Micellar and Macromolecular Systems, Academic Press, New York, 1975.

65 I. A. Khan, M. Bano and Kabir-ud-Din, J. Dispersion Sci. Technol., 2010, 31, 177. 